\title{
Research on the Coupling Relationship Between Hand-drawn and Computer Mapping in Environment Art Design
}

\author{
Anmin Liu \\ Art Institute, Jiujiang University, Jiujiang, China \\ liu_anmin@126.com
}

Keywords: computer science and technology; computer mapping; CAD; environmental art design; coupling relationship; evolution equation

\begin{abstract}
With the rapid development of computer science and technology, the software of computer mapping is emerging in endlessly. The appearances of these cartographic softwares have a huge impact on traditional hand-drawn. The paper explains that the effect of hand-drawn and computer mapping on Environment ART. It clearly expresses the two ways in Environment ART which supplements each other. Both of them are indispensable and the effects of them are different in modern Environmental ART. Then, the paper adopts the analysis method of coupling relationship. It has been discussed and analyzed about the relationship of the two mapping pattern. Therefore, it is conformed that both of the two ways need to be combined and complemented each other. It is essential to consider the situation in the specific project, and arrange the applications of the two designs. At the same time, the paper studies the relationship between the two designs, it is hoped to bring the theoretical reference to the practical design.
\end{abstract}

\section{Introduction}

Environment ART which is the designer to conceive and plan the environment that is needed to be designed, and the specific scheme will be presented finally. It is usually expressed the designer's idea by hand-drawn and computer mapping. People can see project the final result of the project in advance. Hand-drawn is essential to the designer in the late 90s. However, with the popularity of computer, people began to use computer mapping to replace hand-drawn[1]. The way of hand-drawn is being abandoned by some designers. The relationship of hand-drawn and computer mapping is studied in this paper. Firstly, the advantages and disadvantages of hand-drawn and computer mapping are described. Then, the coupling relationship of both is researched. Ultimately, there is a detail description about the role of Environment ART. The method which is used in the paper can also be used in other subject to solve the related problem, and provides theoretical reference for later study[2].

\section{Environment ART}

A. The introduction about environment art design

Its English full name is Environment ART. It is an assortment following the ART. It consists of the design for beautify the environment, landscape and so on. It is belongs to the art design of spatial planning, and has strong comprehensiveness. Environment ART includes the design of environment and surrounding facilities, lighting as well as material and color scheme and so forth[3]. There are two methods which are hand-drawn and computer mapping currently.

B. The current situation and prospects of environmental art design

Art design has started relatively late in China. But as reform and opening up and the increasing improvement of life quality, people begin to pay attention to their living environment and living space. Because of that reason, Environment ART has developed rapidly[4]. However, Environment ART in China is facing a problem that how to deal with time and space, how to solve personalize issue and so on. From the data of Figure 1, it can be seen that our designers have ignored the handdrawn and only pay more attention to computer mapping. Moreover, domestic administration has severely constrained the artistic quality of Environment ART. In public, people seldom take 
participate in Environment ART. The designers' idea is lack of local characteristics and the styles of the time. During the process, they are also lack of caring for natural environment factors. In college, it is short of the training of the designer and teachers for education. It results in disorderly in specialized design of Environment ART in college. Despite of a number of problems, the development of overall aspects is optimistic. Environment ART will maintain the idea of sustainable development in future[5]. According to this idea, it will be formed with respect for the natural environment, considerable for entirety framework and intensive design. Only to meet such requirements, will the environment of people's life be more beauty and the living space be more purified.

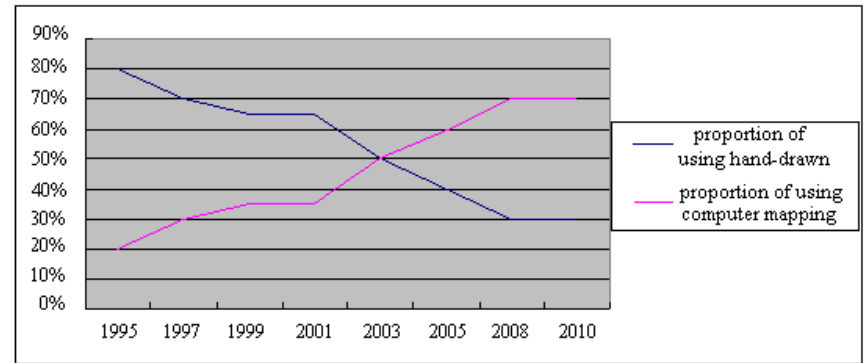

Figure 1. The proportion of using hand-drawn and computer mapping

\section{The function of hand-drawn and computer mapping in Environment ART}

Hand-drawn has a long history in art design. Because of its unique fast performance ability, handdrawn has been basic skill in art design. At the beginning of design, hand-drawn can express the basic idea of design accurately[6]. This is the first step of design conception. From the hand-drawn drawing (as shown in Figure 3), you can see that hand-drawn which can capture designer's idea, so that the creativity of recipients can be similar with designer. It can be recorded the deep creating passion of the designers vividly, forming the visual graphic language in hand-drawn drawings. With the development of science and technology, computer mapping has been greatly improved. It has promoted the rapid development of Environment ART. From computer mapping (as shown in Figure 4), you can see its verisimilitude, and ordinary non-professional users can clearly understand the intention of the designers. So computer mapping has been an important part of the drafting currently. From what has said above, hand-drawn and computer mapping are closely linked and supplemented each other. Only by grasping these two methods, can the alternative of Environment ART be better completed.

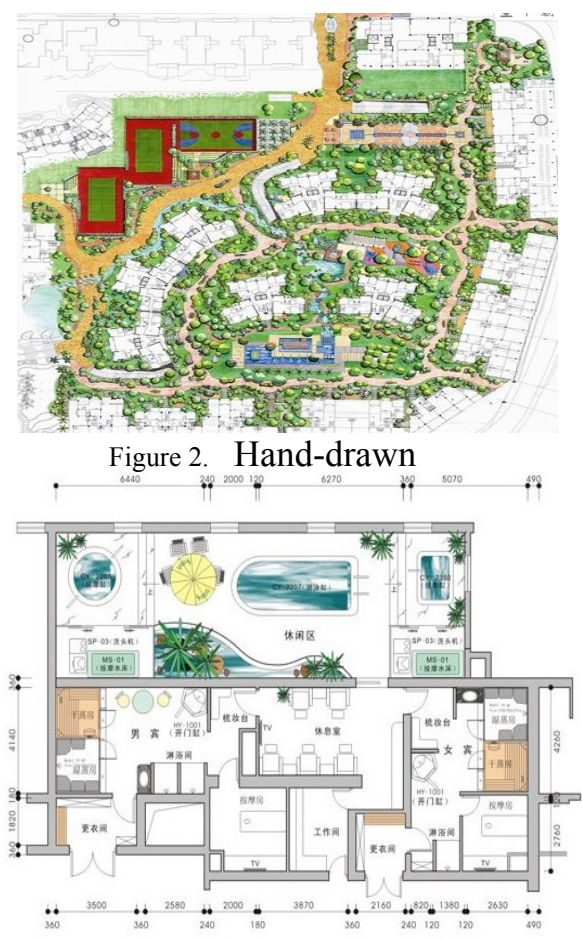

Figure 3. Computer mapping 


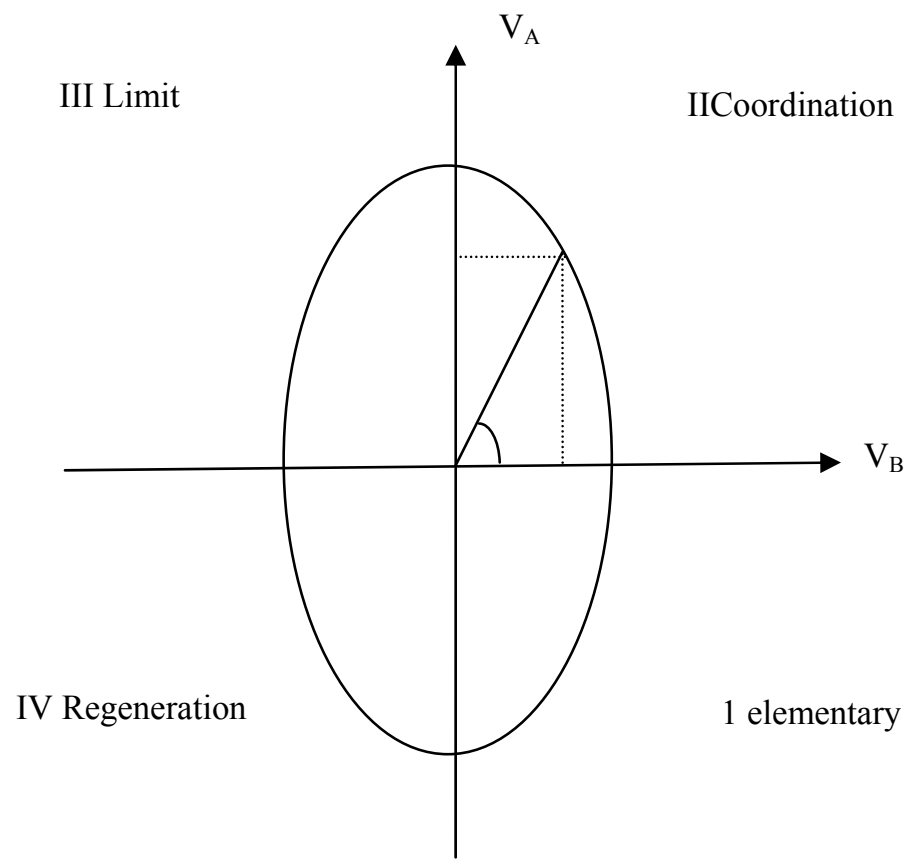

Figure 4. The expression of coupling relationship by the idea of Environment ART

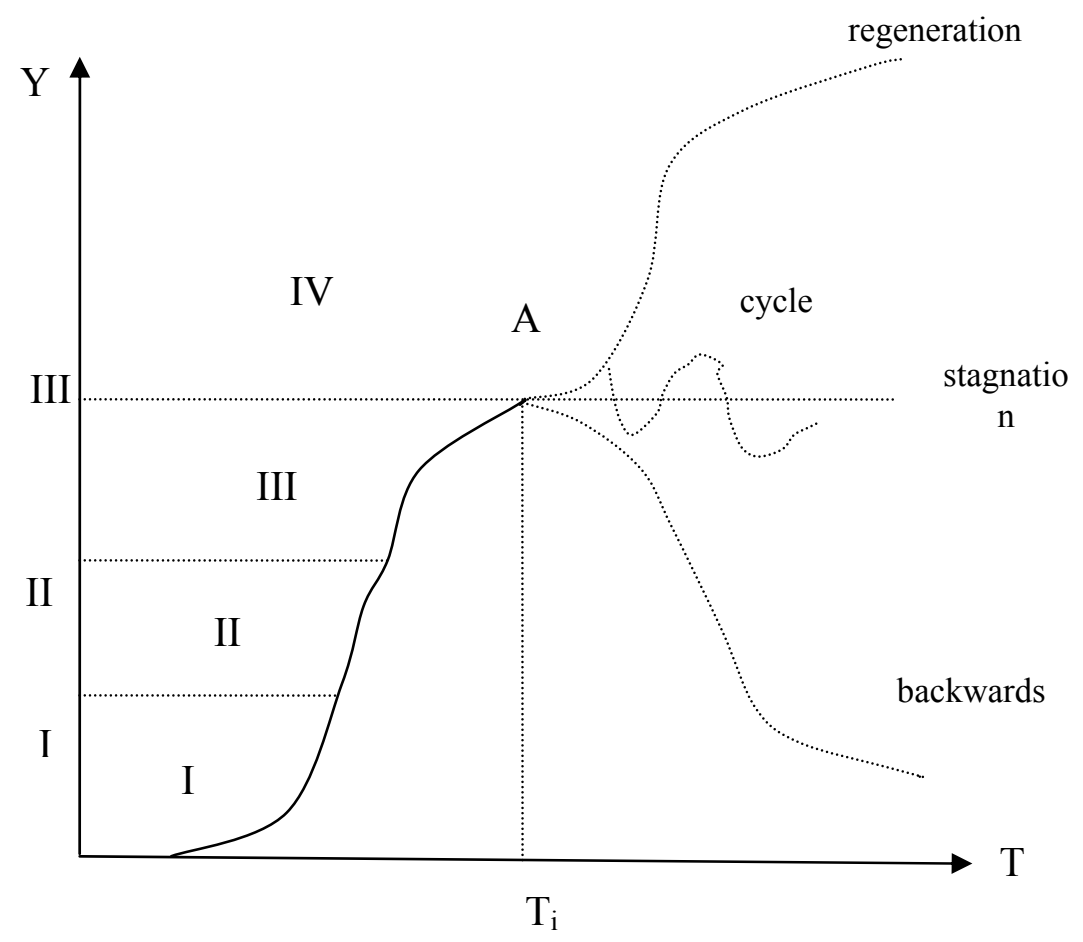

Figure 5. Environmental ART expression of coupling relation evolution model

\section{Teaching practice analysis based on the information technology}

From the better understanding of the function of hand-drawn and computer mapping what has mentioned above, it can be clearly seen that hand-drawn and computer mapping is of great significance to the idea of Environment ART. The advantages and disadvantages between them can be complemented, both of which can support each other. Moreover, they can provide the rational use of design pattern for designers. The two methods will be analyzed by using coupling relationship. First, it can be learned that the methods of hand-drawn and computer mapping are non-linear, and have the coupling relationship, its evolution equation is[7]: 


$$
\frac{\mathrm{dx}(t)}{d t}=f\left(X_{1}, X_{2}, \ldots \ldots, X_{n}\right), \quad i=1,2, \ldots \ldots, n
$$

According to Lyapunov's first approximation theorem, it can be expanded near the original by Taylor series. Then, omitting the higher-order terms, the formula can be written as[8]:

$$
\frac{\mathrm{dx}(t)}{\mathrm{d} t}=\sum_{i=1}^{n} a_{i} x_{i}, \quad i=1,2, \ldots \ldots, n
$$

Therefore, the normal function of hand-drawn and computer mapping in Environment ART is[9]:

$$
\begin{aligned}
& Q_{1}=\sum_{i=1}^{n} a_{i} x_{i}, \quad i=1,2, \ldots \ldots ., n \\
& Q_{2}=\sum_{j=1}^{m} b_{j} y_{j}, \quad j=1,2, \ldots \ldots ., m
\end{aligned}
$$

In the view of the mutual coupling relationship of hand-drawn and computer mapping in Environment ART, it can be studied by serving them as an entirety complex design, so its evolution equation is[10]:

$$
\left\{\begin{array}{l}
A=\frac{d Q_{1}}{d_{t}}=f_{1}\left(Q_{1}, Q_{2}\right) \\
B=\frac{d Q_{2}}{d_{t}}=f_{2}\left(Q_{1}, Q_{2}\right)
\end{array}\right.
$$

A, B are represented the evolution statements which have been influenced by some factors of the two methods of hand-drawn and computer mapping in Environment ART. You can know that the evolution statements of $\mathrm{A}$ and $\mathrm{B}$ are interacting. If $\mathrm{Q} 1$ and $\mathrm{Q} 2$ change, $\mathrm{A}$ and $\mathrm{B}$ will change as well. On the contrary, A or B changes, it will lead to the change of Q1 and Q2, and even the change of entirety design. Therefore, it can be concluded that any factor changes which is dependent on other elements, entirety design method is regarded as a group. The speed of evolution of the two methods is:

$$
V_{A}=\frac{d A}{\mathrm{~d} t}, V_{B}=\frac{d B}{d t}
$$

$\mathrm{V}_{\mathrm{A}}, \mathrm{V}_{\mathrm{B}}$ is respectively represented for the speed of evolution of the two methods. The speed of entirety design $\mathrm{V}$ can be served as the function of VA, VB. When the two methods are coordinated, the entirety design is also developed harmoniously. Because A and B are in an interrelationship in entirety design, and any change of methods will change the whole methods, so there is $\mathrm{V}=\mathrm{f}$ (VA, VB), as VA, VB being control variable. It can be studied the method of entirety design and coupling relationship of two methods by analyzing its change. A combination of these two methods is to achieve optimal integrated approach. As for the specific combination, it must be combined with the two methods of hand-drawn and computer mapping according to the practical subject. Only by this way, can the designer have clear thinking and high efficiency during the design process to complete the high quality alternative.

As the evolution speed of entirety design in Environment ART meets the development mechanism of combination type $\mathrm{S}$, the evolution speed of hand-drawn has been periodically, the evolution speed of computer mapping will also be periodically because of the evolution speed of hand-drawn's influence. In each cycle, V is changed which is caused by VA, VB. So, as VA, VB being variable quantity, you can set up a coordinate system to analyze $\mathrm{V}$ in 2D plane (VA, VB), the change trajectories of $\mathrm{V}$ is an ellipse in coordinate system (as shown in Figure 5). The Figure shows that the intersection $\alpha$ of $\mathrm{V}, \mathrm{VB}$ is contented with $\operatorname{tg} \partial=\frac{V_{A}}{V_{B}}$, so there exists the following formula:

$$
\alpha=\operatorname{arctg} \frac{\mathrm{V}_{\mathrm{A}}}{\mathrm{V}_{\mathrm{B}}}
$$

According to the changes of $\alpha$, you can certain the evolution statement of entirety design, and reveal the degree of coupling between hand-drawn and computer mapping. Obviously, the entirety design will experience elementary, coordination, and limit and regeneration in a periodic evolution (as shown in Figure 6). 
When $-90 \mathrm{o}<\alpha \leq 0 \mathrm{o}$, the entirety design is in elementary. The idea of ability of expression idea in Environment ART is inferior in this period. The usage rate of computer mapping is large, the effect of hand-drawn and computer mapping is not obvious.

When $0 \mathrm{o}<\alpha \leq 90 \mathrm{o}$, the entirety design is in coordination. The effect of hand-drawn and computer mapping is obvious. When $\alpha$ equals to 450 , Environment ART expresses optimum. When $\alpha$ is close to 0 o or $90 \mathrm{o}$, Environment ART expresses discordant.

When $900^{\circ}<\alpha \leq 180 \mathrm{o}$, the entirety design is in limit. Due to the mechanical of computer mapping, the expression of hand-drawn in Environment ART has been limited. It starts to decline from limit. The contradiction between hand-drawn and computer mapping has been increasingly prominent, and eventually leading to the breakdown of entirety design.

When $-180 \mathrm{o}<\alpha \leq-90 \mathrm{o}$, the entirety design is in regeneration. The old design will be broken down and new design will be produced, because the expression designs of hand-drawn and computer mapping in Environment ART are not obvious.

\section{Conclusion}

With the reform of modern teaching pattern, information technology is bound to apply in various disciplines teaching, this technology has also brought great convenience to sports teaching, compared with traditional teaching, the sports teaching based on information technology has great advantages. In the practical teaching link, the sports teaching based on information technology should absorb multimedia teaching and the traditional teaching advantages, complementarity, mutual complement, in order to obtain better teaching effect.

\section{References}

[1] Li Yanzu. Environment ART. China Renmin University Press, 2009:475-477.

[2] Zhu Chun. Expression of Environmental Design. Shanghai People's Fine Arts Publishing House, 2008:329-337.

[3] Wang Shuliang, Zhang Yuhua. History of Modern Design.Chongqing University Press, 2010:174-179

[4] Xiang Bo. The analysis about the relationship of hand-drawn and computer mapping in Environment ART. Journal of Jiamusi Education Institute,2011(9):65-68.

[5] Huang Gang, Wang Binghua, Chen Yufa. The analysis about the current situation and development of Environment ART. Science and Technology Innovation Herald, 2008:1123-1127.

[6] Wang Shouzhi, A History of Modern Design. China Youth Publishing Group, 2005:247-249.

[7] Fu Zongrong. Hand-painting Techniques of Landscape Design. China Architecture \& Building Press, 2011:178-179.

[8] Shao Luoyang. Dictionary of Chinese Art. Shanghai Lexicographical Publishing House, 2012:77-83

[9] Shao Long, Zhao Xiaolong. Expression for Design. China Architecture \& Building Press, 2011:89.

[10] Zheng Shuyang, Interior Design Intellection \& Means. China Architecture \& Building Press, 2012:67-69. 